\title{
Potential of Selective Serotonin Reuptake Inhibitors in preventing clinical deterioration of COVID-19
}

\author{
TATHAGATA BISWAS ${ }^{1}$, BISWA MISHRA ${ }^{2}$, SOURIN BHUNIYA ${ }^{1}$, RITUPARNA \\ MAITI $^{1}$, DEBADATTA MOHAPATRA ${ }^{1}$, and SANTANU NATH ${ }^{2}$
}

${ }^{1}$ All India Institute of Medical Sciences - Bhubaneswar

${ }^{2}$ All India Institute of Medical Sciences Bhubaneswar

January 12, 2021

\begin{abstract}
COVID-19 has an unpredictable course with substantial percentage of infected patients developing clinical deterioration and increasing health care burden. With no specific treatment or vaccination, the current search is for drugs that can limit the disease progression. Recently Fluvoxamine has been reported to have disease modifying effects in COVID-19. We suggest the hypothesis that short term routine use of Selective Serotonin Reuptake Inhibitors (SSRIs) can prevent clinical deterioration of asymptomatic or mild COVID-19 cases by the following ways: a) anti-inflammatory actions through sigma- 1 agonism and reducing release of pro-inflammatory cytokines, b) anti-coagulant action by reducing platelet aggregation, c) specific antiviral and antibacterial effects, d) Immunomodulation through Serotonin pathway and anti-oxidation. The routine short term use of SSRIs can also alleviate the psychological impact of the disease. We hope our hypothesis will encourage future clinical trials to validate the routine use of SSRIs against COVID-19.
\end{abstract}

\section{Hosted file}

Main_document.pdf available at https://authorea.com/users/389054/articles/503706-potentialof-selective-serotonin-reuptake-inhibitors-in-preventing-clinical-deterioration-ofcovid-19 


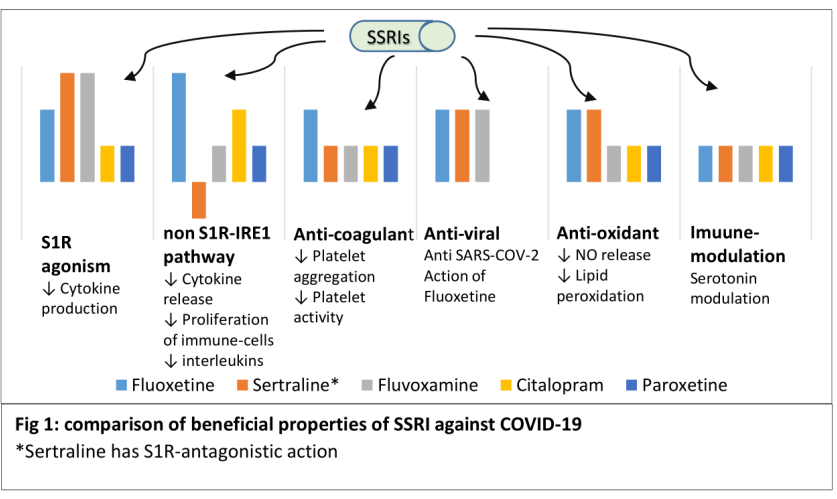

